\title{
DNA/RNA Degradation Rate in Long Term Fixed Museum Specimens
}

\author{
Shannon Cook, Chelsea Dodge, Randy Morgan, George E. Sandusky \\ Pathology Department, Indiana University School of Medicine, Indianapolis, USA \\ Email: shlcook@imail.iu.edu, chedodge@iupui.edu, radmorga@iupui.edu, gsandusk@iupui.edu
}

Received 21 October 2014; revised 28 November 2014; accepted 10 December 2014

Copyright (C) 2015 by authors and Scientific Research Publishing Inc.

This work is licensed under the Creative Commons Attribution International License (CC BY).

http://creativecommons.org/licenses/by/4.0/

(c) (i) Open Access

\begin{abstract}
In today's research driven society, it has become commonplace for institutions to rely upon DNA and RNA extraction techniques to help obtain genomic data from old specimens. Generally, specimens are preserved for future gross examination and/or teaching. Using histological examination of specimens from museum jars from the Pathology Department at the Indiana University School of Medicine, the sequential and chronological degradation of DNA and RNA has been studied. We examined gross specimens from 1920 to 2000 . We evaluated histologic preservation of kidney, liver, heart, lung, spleen, uterus and brain for nuclear structure in these samples. Nuclear preservation was based on amount of nuclei per microscopic field and the crispness of the nuclear membrane and internal features. The nuclei in high lipid tissues such as the brain were found to degrade at a quicker rate than dense tissues such as the heart and uterus. Our study has shown that specimens preserved beyond fifty years were likely to have little to no nuclei left, thus indicating that there was little to no DNA and RNA remaining. This technique of histologic evaluation is an important finding and a general guideline which may save research institutions from the expensive process of DNA and RNA extraction.
\end{abstract}

\section{Keywords}

DNA, RNA, Nuclear Degradation, Microscopy

\section{Introduction}

Historically, a variety of fixatives — such as various concentrations of alcohols and formalin - have been used; presently, the accepted fixative is $10 \%$ neutral buffered formalin. Formalin has a primary mechanism of fixation by way of cross linking proteins, thereby causing the fixed substance to become firmer than that in situ. Within reasonable time frames formalin may also still provide a suitable medium for genomic study, such as DNA and 
RNA extraction [1].

First prepared in 1859, formalin did not undergo commercial production in the United States until 1901. Formalin was first used for preservation of tissue samples for purposes such as histology, gross anatomy, cytology and taxonomy. Only within the past two decades formalin has begun to be used for archival collections for DNA-related purposes. Within $6-8$ months, formalin begins the chemical breakdown process into formic acid; further reactions due to long exposure to formalin have not been well characterized. Due to the nature of the breakdown process of formaldehyde, it is not a suitable medium for long term preservation of DNA. Instead, tissue for molecular studies is commonly either frozen or fixed in alcohol. Even short term specimen storage in formalin has been shown to significantly reduce DNA and RNA solubility. There is considerable evidence to show that formaldehyde induces DNA and RNA degradation [2]-[6].

Upon removal from the body, tissues undergo an autolytic process initiated soon after cell death causing breakdown of proteins and eventual liquefaction of the cell. Fixation is a preservation method commonly used to preserve cells and tissues as close to a life-like state as possible, while still allowing them to undergo further preparative procedures and examinations without change. As fixation stabilizes cells and tissues through cross linking proteins, autolysis and bacterial decomposition are arrested. Fixation rate in dense tissues, such as the heart and uterus, can be very slow; direct injection of fixative can increase the rate of fixation.

DNA and RNA recovery is important to many scientific disciplines and medical specialties. Of special interest is forensic anthropology. Forensic anthropologists are often responsible for recovering century old artifacts and evidence. Although specimens recovered in this fashion are often not preserved by chemical fixation, our study may still serve as a basic guideline which can be used for extrapolation for nuclear genomic material recovery in aged and unpreserved specimens. A limitation of our study is that it can't be extrapolated for mitochondrial genomic material analysis, which is often used in forensic anthropology.

\section{Materials \& Methods}

All of the data was collected after a detailed IRB approved protocol. Upon breaking the seal on the museum jars, sections of tissue were taken for processing and analysis. Ten specimens from each decade consisting of various organs such as brain, kidney, liver, heart, lung, spleen, and uterus were included in the study. Grossly, all organs looked intact, and lesions (hemorrhages, necrosis, inflammation and tumors) could still be seen in the tissues. DNA extraction on FFPE tissues was performed for a previous study. The results of that study were incorporated into this current study.

Tissue Processing: The tissues are fixed overnight in neutral buffered formalin and then transferred to $70 \%$ ethanol prior to processing to a paraffin block. The $3.5 \times 2.5$ slides were then baked overnight $@ 59^{\circ} \mathrm{C}$ in an oven before staining with $\mathrm{H} \& \mathrm{E}$ (Hematoxylin and Eosin).

Slide Evaluation: Three investigators QCd the various slides by light microscopy to evaluate the following information. Results were blinded between investigators. Our histology specifications for histologic scoring were the following: the nuclear preservation and/or the loss of cellular nuclei on a slide were scored as $0=$ negative or no loss, $1=$ minimal (less than $25 \%$ nuclei affected), $2=$ moderate $(25 \%$ to $50 \%$ nuclei affected), $3=$ severe $(50 \%$ to $75 \%$ nuclei affected), and $4=$ marked (all nuclei affected).

Molecular Analysis: DNA extraction on FFPE tissues: The block was microtomed to cut $10-40 \mathrm{mg}$ of tissue. The tissue was placed in $2 \mathrm{ml}$ cryovials and rinsed with xylene. The vials were vortexes and centrifuged using an Eppendorf centrifuge at $13 \mathrm{rpm}$ for 15 minutes. The supernatant was removed, and the ethanol rinse was repeated. The cryovials were left uncovered for 15 minutes before $1 \mathrm{ml}$ of isopropanol was added. The vials were soaked for 14 hours. The samples were centrifuged and the supernatant was decanted, leaving only tissue. The tissue was homogenized for 30 seconds. Then, $240 \mu \mathrm{L}$ of M1 reagent and $250 \mu \mathrm{L}$ of M2 solution from the Autogen kit AFKT-FXTD were added to all cryovials and PK solution was made with a concentration of M1 solution to $50 \mathrm{mg}$ of PK. Ten microliters of the PK solution was added to all tissue samples, and the vials were left to rotate in an incubator overnight at $55^{\circ} \mathrm{C}$. One milliliter was removed from all samples and added to the Autogen Flexstar machine for DNA extraction. The procedure was completed according to the Autogenmanufacturer's recommendations. A similar procedure was done for liquid storage of tissues. DNA integrity and yield were assessed by determining sample absorbance at 260 and $280 \mathrm{~nm}$ on the Nanodrop 1000 .

\section{Results}

Our study sought to discover what a "reasonable time frame" is for specimens stored in formalin that may still 
allow DNA and RNA extraction. Although there is variance between lipid and protein based structures, our study found that specimens preserved roughly beyond fifty years are likely to have little to no nuclei, and consequentially a low likelihood of success for DNA and RNA extraction. Other factors besides length of storage time and biological make-up of the fixed specimen influence whether or not DNA and RNA extraction is successful; these factors include size of specimen, duration of tissue hypoxia, and chemical composition of fixative [7].

The tissues (kidney, liver, heart, lung, spleen, uterus, and brain) were in a state of good histologic preservation with retention of nuclei, cytoplasm and cell membrane in most tissues collected after 1960. In general, tissues collected before 1960 showed cell structure degradation with dissolution of some nuclei, washed out cell cytoplasm, and some cell membrane dissolution. These degenerative features were observed to be more severe in the kidney, liver, lung, spleen, and brain than the heart and uterus. The heart and uterus had moderate nuclear loss at the 1920 time frame (see Figures 1-7).

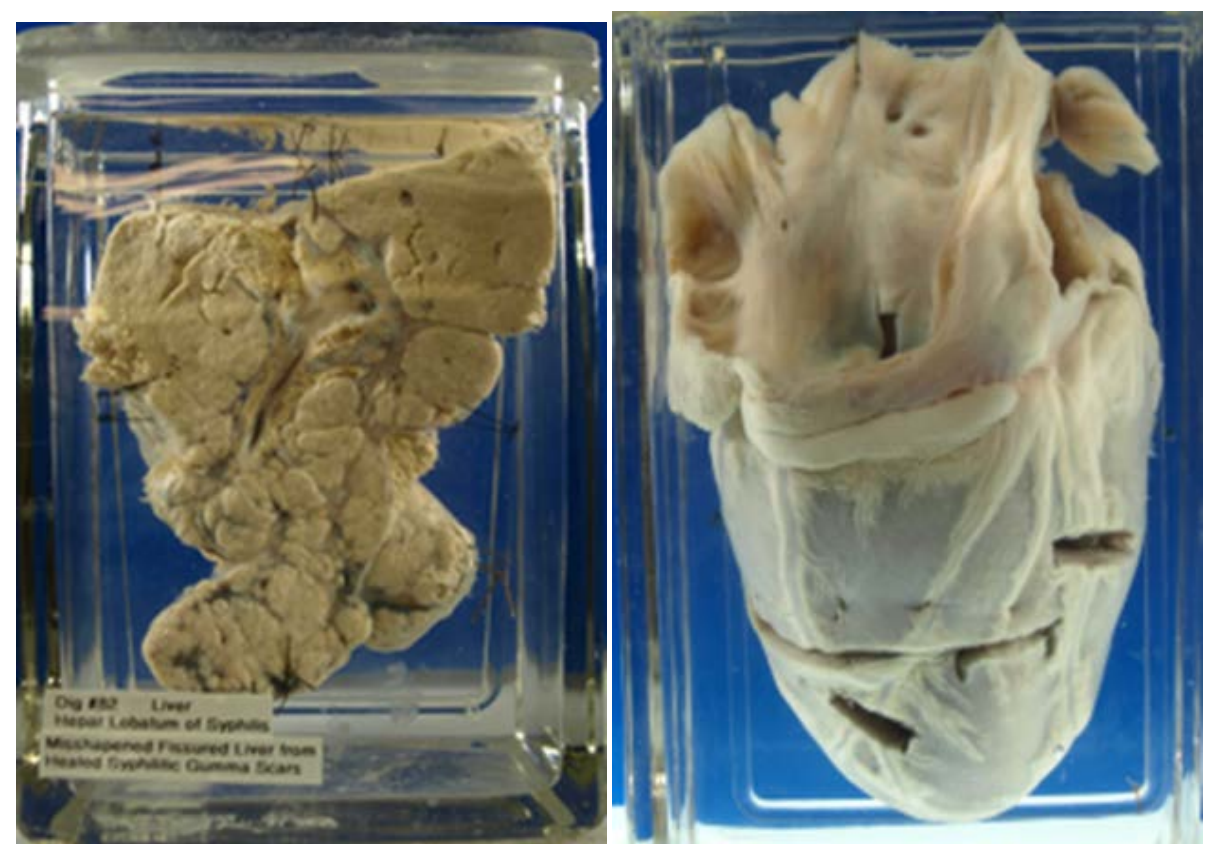

Figure 1. Museum jars from Indiana University School of Medicine. Preserved organs such as the liver and heart had higher rates of cellular structural preservation compared to those of organs such as the brain.

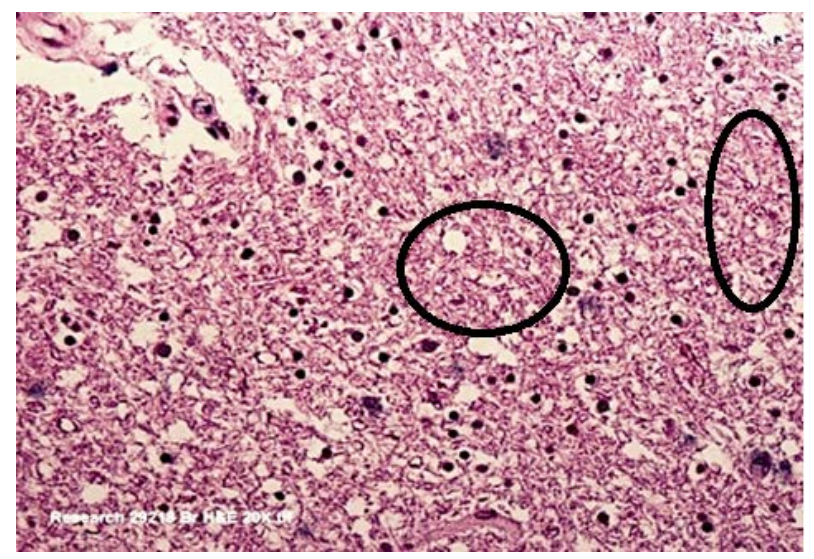

Figure 2. Brain tissue with minimal nuclei degradation (15 year storage, the 1980s) H \& E 20X magnification. Circled areas highlight nuclear degradation. 


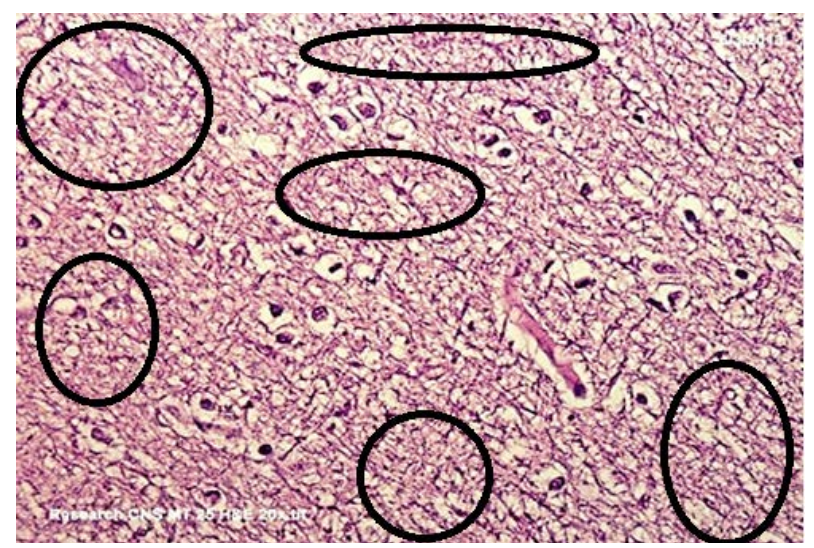

Figure 3. Brain tissue with moderate nuclei degradation (25 year storage, the 1970s) H \& E 20X magnification. Circled areas highlight nuclear degradation.

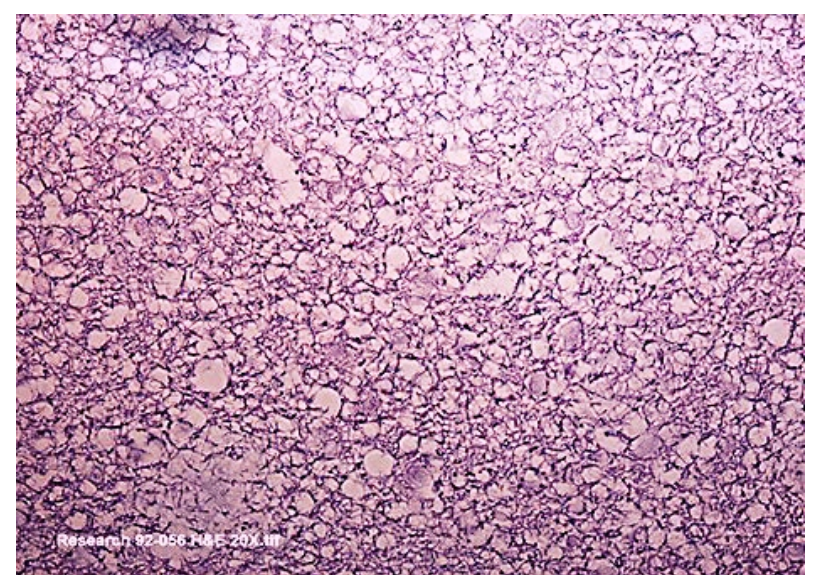

Figure 4. Brain tissue with complete nuclei degradation (80 year storage, the 1920s) H \& E 20X magnification. Nuclear degradation not manually highlighted due to entire representative section being patently affected by nuclear degradation.

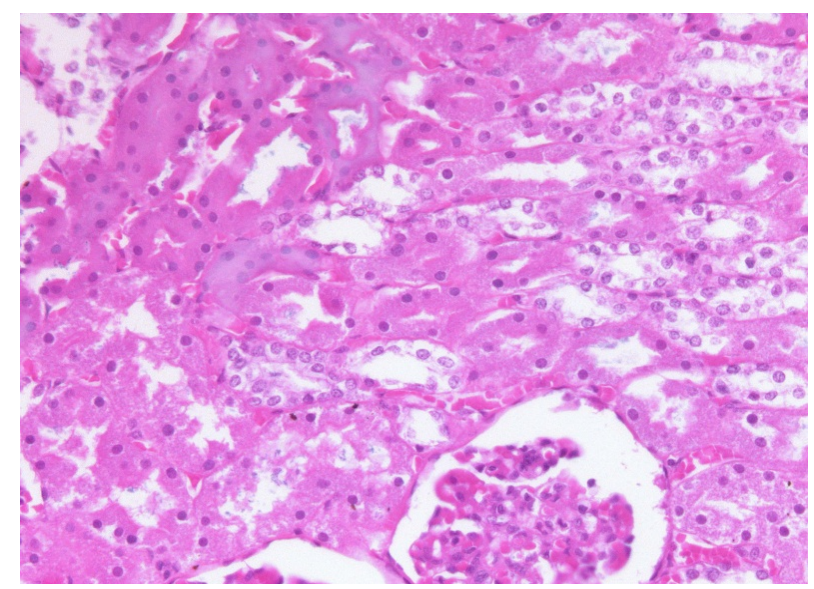

Figure 5. Kidney tissue with minimal nuclei degradation (the 1960s) H \& E 20X magnification. Nuclear degradation not manually highlighted due to the fairly even presence of intact nuclei present throughout representative section. 


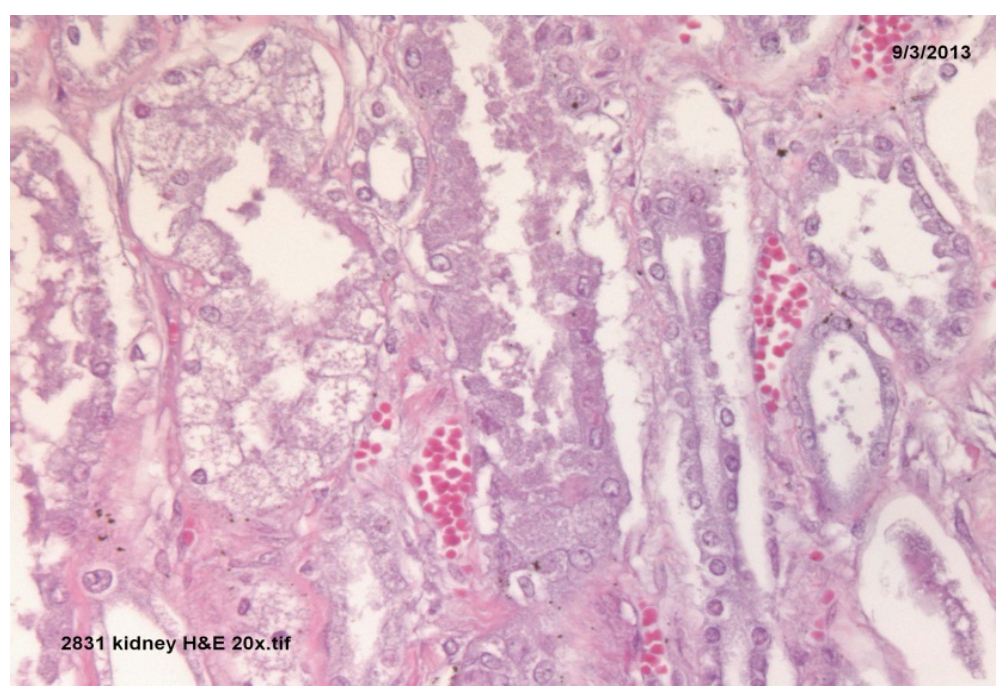

Figure 6. Kidney tissue with complete nuclei degradation (the 1930s) H \& E 20X magnification. Nuclear degradation not manually highlighted due to entire representative section being patently affected by nuclear degradation.

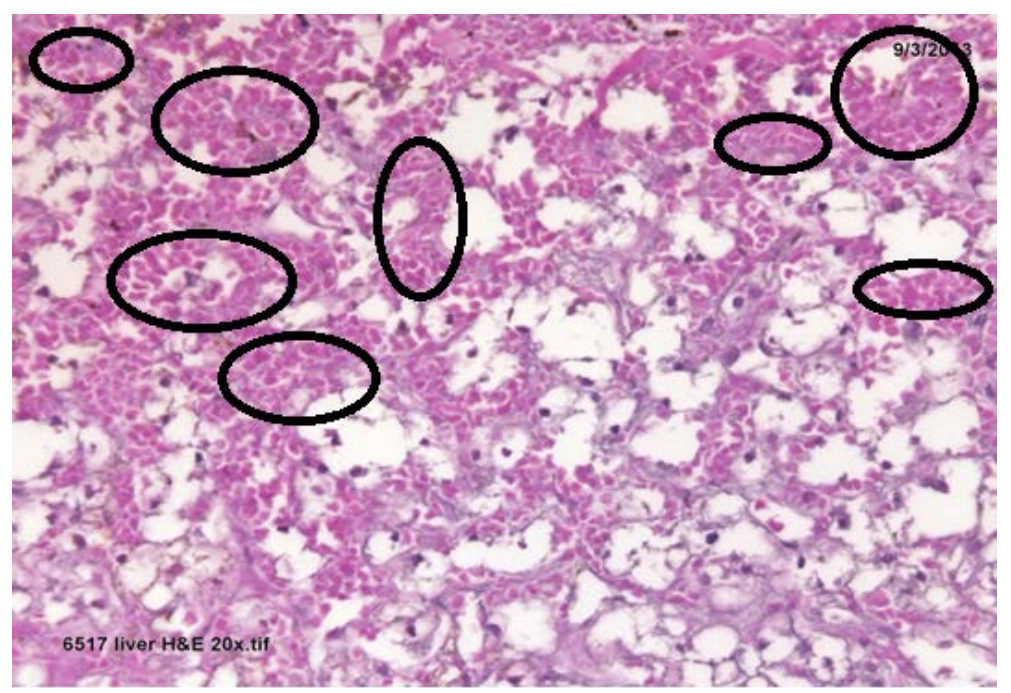

Figure 7. Liver tissue with moderate nuclei degradation (the 1940s) H \& E 20X magnification. Circled areas highlight nuclear degradation..

The fixation preservation in which the tissues were preserved was also considered when analyzing the molecular structural integrity of the nucleic acids. The highest percentage of DNA yield and concentration was found in specimens which were formalin fixed/paraffin embedded. These samples were followed by specimens fixed in celloidin. Specimens stored in both formalin fixed/ethanol stored and unbuffered formalin have been found to have a significantly lower DNA concentration than the preceding two preservation methods.

\section{Discussion}

First discovered in 1859 , formaldehyde has been the standard fixative for preserving tissues. It has proved useful in long term storage of gross organs and consequent microscopic examination. Old gross organ tissues that have been stored for decades are now being used for genomic and molecular examination. In the past 10 years, decade old tissues collected and stored in formalin fixed paraffin embedded blocks have been used for DNA and RNA profiling [4] [8]. The other main source of tissue has been gross specimens that have been fixed and stored in glass museum jars. Many museum specimens have been changed from formalin to alcohol for long term sto- 
rage. Genomic research using both methods of tissue preservation is being used today for DNA and RNA molecular research [9].

Various concentrations of formaldehyde have been used since the late 1800s to the 1960s; formalin was often not buffered or properly diluted. Presently, both the medical community and museum gross specimen collections in long term storage utilize 10\% neutral buffered formalin [9]. Recent molecular studies have shown high quality and high yield of DNA/RNA can be obtained from these tissues that have been stored in a paraffin block that was fixed in 10\% neutral buffered formalin. Our previous work indicated that tissue fixed in celloidin or paraffin for 70 plus years preserved DNA to a degree that was better than tissues left in formalin or in $70 \%$ ethanol for many years [10]. Formalin degrades DNA, RNA, and proteins via interaction between DNA hydrogen bonds and cross linkage between the proteins and DNA. Previous studies have shown that the degradation of DNA/RNA, lower quality, and lower yield, occurs after about 1 year. Other studies have shown that some tissues retain useful DNA/RNA for up to 85 years [1] [7].

\section{Conclusion}

This study was designed to investigate if viable cellular nuclei in the tissues which had been stored in formalin over an extensive time period from the 1920s to the 1990s survived. If so, DNA/RNA can be extracted for genomic research. Histologic evaluation revealed cellular nuclei containing high levels of DNA in samples from the 1940s and forward. Specimens preserved in the 1920s had dissolved nuclei with little DNA/RNA extracted due to loss of nuclei. The current study is very similar to other previous studies that have been done in these types of tissues. This study suggests that performing routine histology can usually indicate the success of DNA/RNA extraction in old museum specimens, whether paraffin blocks or gross organ specimens, if the nuclei are still visible and intact.

\section{References}

[1] Miething, F., Hering, S., Hanschke, B. and Dressler, J. (2006) Effect of Fixation to the Degradation of Nuclear and Mitochondrial DNA in Different Tissues. Journal of Histochemistry \& Cytology, 54, 371-374.

[2] Stephen, M., Hewitt, M.D., et al. (2008) Tissue Handling and Specimen Preparation in Surgical Pathology Issues Concerning the Recovery of Nucleic Acids from Formalin-Fixed, Paraffin-Embedded Tissue. Archives of Pathology \& Laboratory Medicine, 132, 1929-1935.

[3] Xie, R., Chung, J.-Y., Ylaya, K., Williams, R.L., Guerrero, N., Nakatsuka, N., Badie, C. and Hewitt, S.M. (2011) Factors Influencing the Degradation of Archival Formalin-Fixed Paraffin-Embedded Tissue Sections. Journal of Histochemistry \& Cytochemistry, 59, 356-365. http://dx.doi.org/10.1369/0022155411398488

[4] Jewell, S., Sedmak, D. and Srinivasan, M. (2002) Effect of Fixatives and Tissue Processing on the Content and Integrity of Nucleic Acids. American Journal of Pathology, 161, 1961-1971.

[5] Klopfleisch, R., Weiss, A.T. and Gruber, A.D. (2011) Excavation of a Buried Treasure-DNA, mRNA, miRNA and Protein Analysis in Formalin Fixed, Paraffin Embedded Tissues. Histology and Histopathology, 26, 797-810.

[6] Turashvili, G., Yang, W., McKinney, S., Kalloger, S., Gale, N., Ng, Y., Chow, K., Bell, L., Lorette, J., Carrier, M., Luk, M., Aparicio, S., Huntsman, D. and Yip, S. (2011) Nucleic Acid Quantity and Quality from Paraffin Blocks: Defining Optimal Fixation, Processing and DNA/RNA Extraction Techniques. Experimental and Molecular Pathology, 92, 3343. http://dx.doi.org/10.1016/j.yexmp.2011.09.013

[7] Stan, A.D., Ghose, S., Gao, X.-M., Roberts, R.C., Lewis-Amezcua, K., Hatanpaa, K.K. and Tamminga, C.A. (2006) Human Postmortem Tissue: What Quality Markers Matter? Brain Research, 1123, 1-11. http://dx.doi.org/10.1016/j.brainres.2006.09.025

[8] Chung, J.-Y., Braunschweig, T., Williams, R., Guerrero, N., Hoffman, K.M., Kwon, M., Song, Y.K., Libutti, S.L. and Hewitt, S.M. (2008) Factors in Tissue Handling and Processing That Impact RNA Obtained from Formalin-Fixed, Paraffin-Embedded Tissue. Journal of Histochemistry \& Cytochemistry, 56, 1033-1042.

[9] Schander, C. and Halaynch, K.M. (2003) DNA, PCR and Formalinized Animal Tissue-A Short Review and Protocols. Organisms Diversity \& Evolution, 3, 195-205. http://dx.doi.org/10.1078/1439-6092-00071

[10] Niland, E.E., McGuire, A., Cox, M.H. and Sandusky, G.E. (2012) High Quality DNA Obtained with an Automated DNA Extraction Method with 70+ Year Old Formalin-Fixed Celloidin-Embedded (FFCE) Blocks from the Indiana Medical History Museum. American Journal of Translational Research, 4, 198-205. 
Scientific Research Publishing (SCIRP) is one of the largest Open Access journal publishers. It is currently publishing more than 200 open access, online, peer-reviewed journals covering a wide range of academic disciplines. SCIRP serves the worldwide academic communities and contributes to the progress and application of science with its publication.

Other selected journals from SCIRP are listed as below. Submit your manuscript to us via either submit@scirp.org or Online Submission Portal.
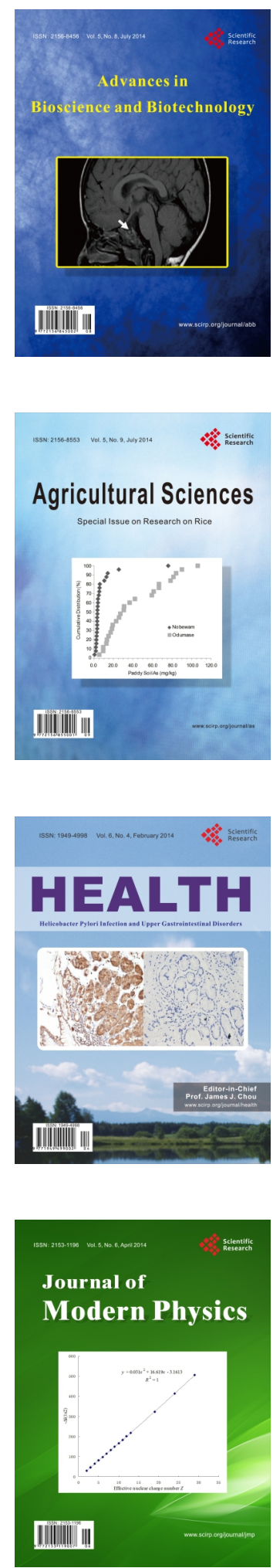
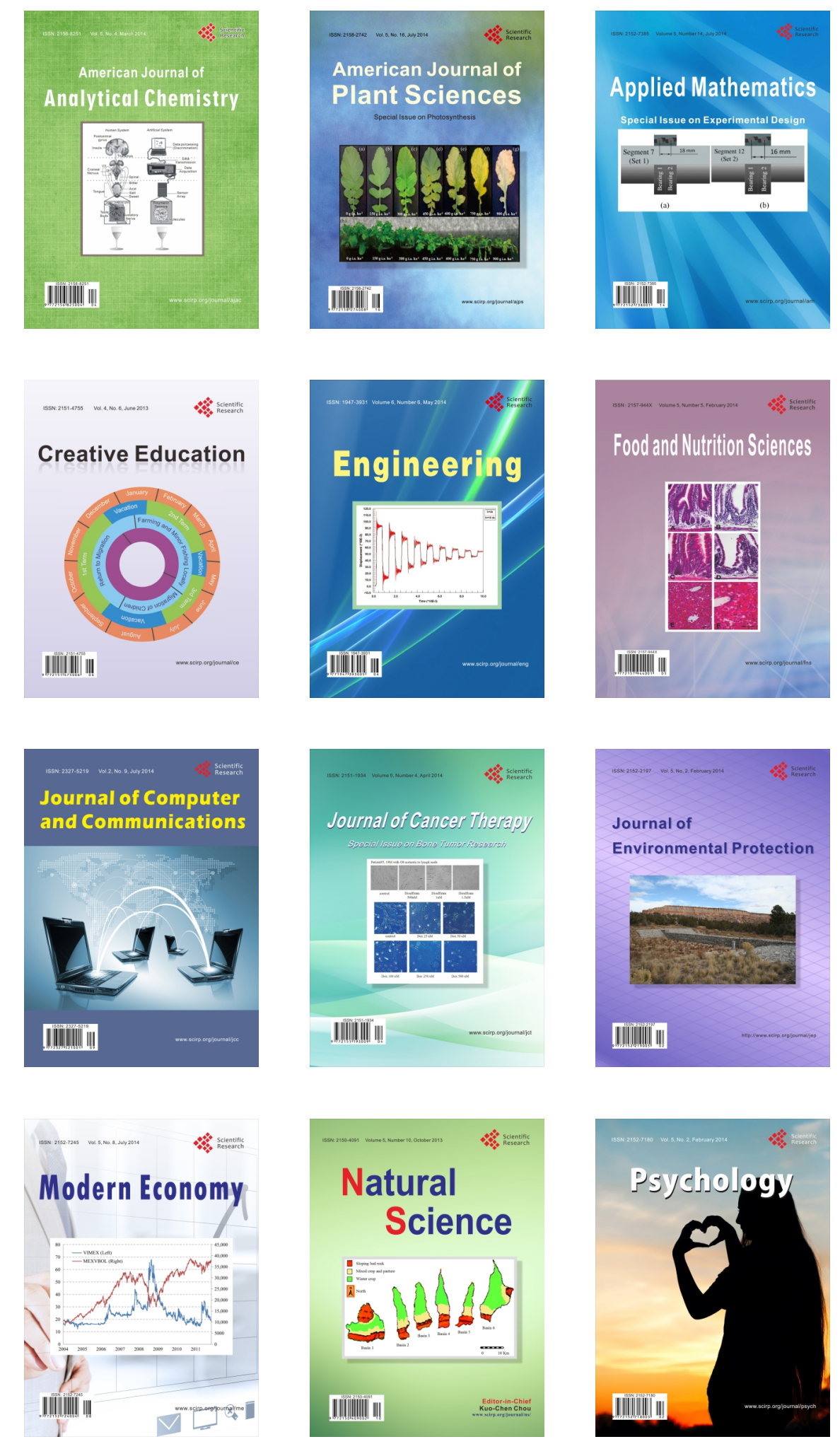